\title{
Comentário:
}

\section{Reforma da assistência médico-sanitária na Grande São Paulo na década de $\mathbf{7 0}$ Reform on medical care assistance in Great São Paulo in the 70's}

\author{
Paulo Eduardo Mangeon Elias \\ Departamento de Medicina Preventiva. Faculdade de Medicina da Universidade de São Paulo. São \\ Paulo, SP, Brasil
}

Foi com grande emoção e deleite que li este belo trabalho ao atender a honrosa tarefa a mim solicitada pelos editores.

$\mathrm{O}$ artigo foi publicado no momento de inflexão na trajetória da saúde pública paulista no qual se transitava da herança de Paula Souza para a era das reformas implementadas por outro grande sanitarista que foi Walter Leser. Datado historicamente, rememora uma época na qual a Secretaria de Estado da Saúde (SES) se apresentava como a grande prestadora de serviços na assistência médico-sanitária (a atenção básica de hoje) e mantinha corpo técnico de grande excelência que se constituía em verdadeira 'inteligência' na atenção básica. Infelizmente, se perdeu quase por completo com o advento da descentralização dos serviços de saúde para os municípios. Nesse sentido o artigo pode ser classificado como um clássico, pois apreende magistralmente aquele momento de virada na saúde pública paulista em que se introduzia a assistência médica na rede básica, sob a égide do médico-sanitarista.

O objetivo do trabalho abarca uma dupla intenção: apresentar criticamente um diagnóstico da rede pública de assistência e a nova estrutura da SES. Essa nova organização de certa forma vigente até o presente é apresentada com grande riqueza de detalhes nos fornecendo boas pistas sobre a lógica organizacional que passa a presidir a SES.

A metodologia descritiva utilizada no trabalho mos-

Correspondência/ Correspondence:

Paulo Eduardo Mangeon Elias

Departamento de Medicina Preventiva -FMUSP

Av. Dr. Arnaldo, $4552^{\circ}$ andar

01246-900 São PAulo, SP, Brasil

E-mail:pemelias@usp.br tra de modo exaustivo e preciso a distribuição territorial dos serviços, compondo um diagnóstico da situação da rede assistencial, sintetizado em cinco tópicos principais: 1) descoordenação entre as esferas de governo e os serviços municipais e estaduais; 2) ausência de critérios técnicos para a localização dos serviços de saúde; 3) distribuição desigual dos serviços de saúde resultando na penalização de amplos contingentes populacionais; 4) deficiências na qualidade dos serviços prestados; 5) insuficiência de meios para se atingirem os fins previstos na reforma em curso.

Não obstante as três décadas e meia que nos separa daquele período nota-se que, em grandes linhas, o discernimento apresentado mantém enorme atualidade ainda que os tempos presentes marquem profundas diferenças com aquele do passado.

Nesses anos ocorreram várias mudanças no cenário mundial e brasileiro que tiveram grande repercussão na estrutura social e econômica do País e por conseqüência na rede assistencial brasileira. Ainda na década de 70 ocorreu a crise do Estado de Bem Estar Social e a emergência do ideário liberal como a solução para o desenvolvimento capitalista nos países democráticos ocidentais. Isso tudo culminou no movimento de globalização com enormes repercussões para os países da periferia do capitalismo para os quais se produz o ideário do "Consenso de Washington", recomendando a austeridade fiscal com o decorrente ajuste nos gastos públicos e as massivas privatizações. O Brasil que experimentava pela primeira vez a urbanização da maioria da população e consolidava o desiderato do ideário nacional desenvolvimentista via-se instado a responder a um novo ordenamento da economia mundial para o qual encontrava-se extremamente despreparado, dada a diversidade dos parâmetros contidos no 
nacional desenvolvimentismo. No campo específico da saúde vale destacar os grandes projetos do período. No âmbito planetário, cita-se o movimento pela universalização da atenção básica de saúde inicialmente patrocinado pela OMS e traduzido pelo slogan "Saúde para Todos" no ano 2000. Posteriormente foi endossado por agências multilaterais tais como o Banco Mundial, em perspectiva bastante diversa do projeto original, ao tempo em que a saúde vai se constituindo como importante setor para a o processo de acumulação de capital.

O grande avanço do processo de empresariamento da saúde com a consolidação das operadoras de planos e seguros de saúde, é secundado pelo advento da Constituição de 1988, que de modo pioneiro conseguiu o princípio da seguridade social e instituiu o Sistema Único de Saúde (SUS). Na década seguinte, o advento do processo de descentralização com a transferência de serviços das esferas centrais para os municípios transforma-os em grandes prestadores de assistência à saúde, situação bastante diversa da descrita pelo artigo publicado.

Não obstante a enorme mudança no panorama do setor saúde verificada no período de 1970 até o presente, em que se sobressaem o significativo incremento na oferta e a ampla melhoria no acesso dos serviços, persistem como problemas praticamente os mesmos cinco apontados pelos autores em seu diagnóstico, ora acrescidos de outros, tais como a complexificação dos procedimentos de diagnose e os terapêuticos, bem como os vinculados ao financiamento do sistema de saúde. Todavia, dentre eles permanecem mais renitentes os reiterados descompassos entre os meios necessários frente aos fins pretendidos, a desigualdade na distribuição dos serviços de saúde e os conflitos entre as esferas de governo. É farta a literatura produzida sobre o tema para comprovar essa assertiva. Numa mesma publicação de 2002, dedicada aos desafios da gestão local, Souza e Viana et al tratam do processo da descentralização da perspectiva do desenho federativo vigente no Brasil e do fenômeno da desigualdade. Souza concluiu pela permanência da desigualdade inter e intra-regional como questão nacional, embora desconsideradas pela agenda de prioridade do País, enquanto Viana et al apontam um processo recente de fortalecimento das instâncias estaduais, desacompanhado dos recursos financeiros necessários às novas funções previstas para estas instâncias.

Vale ainda assinalar que diagnóstico apresentado pelos autores em 1971 contribuiu com outros estudos produzidos naquela época para impulsionar um movimento pelo planejamento de uma rede de serviços. Na década seguinte, essa rede culminou no Plano Metropolitano de Saúde, cujas últimas unidades foram entregues em 2004.

Destarte, trata-se de artigo que fornece elementos do passado recente preciosos para a compreensão e o planejamento futuro das políticas de saúde, inclusive por tratar o tema em termos metropolitanos - fato corriqueiro no período dos governos militares e que só recentemente foi retomado pelos formuladores de políticas públicas.

Em (suma, trata-se de uma preciosidade dentre tantos outros artigos que esta Revista nos tem brindado em seus 40 anos de excelentes serviços prestados à saúde pública brasileira.

Por fim uma palavra sobre um dos autores. João Yunes, homem sábio e muito cordial, foi um gentleman da saúde pública. À seu modo sustentou durante toda a vida um profundo compromisso com as causas da saúde no Brasil e no mundo ao ocupar postos relevantes na OPS-OMS. Seu precoce desaparecimento priva o nosso meio de um espírito inovador e empreendedor associados à maneira gentil de tratar as pessoas. Congratulo-me com os editores pela iniciativa da série de artigos históricos e pela escolha deste, que para além dos méritos já apontados, presta justíssima homenagem a um sanitarista de grande valor e inegáveis méritos.

\section{REFERÊNCIAS}

1. Pochmann M. Proteção social na periferia do capitalismo: considerações sobre o Brasil. São Paulo Perspect 2004;18(2):3-16.

2. Schwartzman S. Pobreza, exclusão social e modernidade: uma introdução ao mundo contemporâneo. São Paulo: Augurium; 2004.
3. Souza C. Governos e sociedades locais em contextos de desigualdades e de descentralização. Ciênc Saúde Coletiva 2002;7(3):431-42.

4. Viana AL, Lima LD, Oliveira RG. Descentralização e federalismo: a política de saúde em novo contexto: lições do caso brasileiro. Ciênc Saúde Coletiva 2002;7(3):493-507. 